\title{
The Impact of Open Access upon Public Health
}

\section{The PLoS Medicine Editors}

\section{rthur Amman, President of Global Strategies for HIV Prevention (http://www.} globalstrategies.org), tells this story:

"I recently met a physician from southern Africa, engaged in perinatal HIV prevention, whose primary access to information was abstracts posted on the Internet. Based on a single abstract, they had altered their perinatal HIV prevention program from an effective therapy to one with lesser efficacy. Had they read the full text article they would have undoubtedly realized that the study results were based on shortterm follow-up, a small pivotal group, incomplete data, and unlikely to be applicable to their country situation. Their decision to alter treatment based solely on the abstract's conclusions may have resulted in increased perinatal HIV transmission."

Amman's story shows the potentially deadly gap between the informationrich and the information-poor. This gap is not the result of lack of technology or of money, but of a failure of imagination. We live in the most information-rich era of history, when the Internet allows immediate global dissemination of crucial health information, and the interlinking of online information creates an integrated, living body of information-the ultimate vision of which is the semantic Web (http://www.w3.org).

What is preventing such a living Web? For scientific and medical information, two obstacles are vested interests and traditions. The role of copyright, which was developed when the dissemination of work was on paper, is crucial. Initially, applying copyright to medical articles protected both the intellectual investment of authors and the commercial investment of publishers. Authors of scientific articles handed over their copyright to publishers to prevent unauthorized print copying. Thus, the prevention of unauthorized copying helped to disseminate information by providing a valid business model for publishers. But the proliferation of subscription-based medical and scientific journals led to readers having to pay more and more to publishers in order to keep up with current knowledge, and also led to an increasing fragmentation of knowledge between different publishers.

The Internet provides the means to revolutionize publishing in two crucial ways. First, it makes it possible to disseminate health information at no charge to anyone in the world with online access. Although it costs money to peer review, edit, produce, and host an online article, this is a onetime, fixed cost. If research funders are willing to pay this cost, then the published work can be made freely available to all readers worldwide, and there would be no need for journal subscriptions. This is one way of financing an open-access model of publishing (http://www.earlham.edu/ $\sim$ peters/fos/overview.htm).

Second, because the internet allows not just ease of access but ease of reuse, an article's usefulness is limited only by a user's imagination. To allow this, the traditional role of copyright has to change. Instead of publishers using copyright to restrict use, authors can retain copyright and grant the public the right to creatively reuse their work. Licenses such as those developed by Creative Commons (http://creativecommons.org), which facilitate rather than prohibit reuse, are used by the open-access publishers PLoS (DOI: 10.1371/journal. pbio.0020228) and BioMed Central (BMC). The result as Jan Velterop, Director of Open Access at Springer, says is that "copyright can be used for what it is meant to in science, not to make the articles artificially scarce and in the process restrict their distribution, but instead, to ensure that their potential for maximum possible dissemination can be realised" (http://www.soros.org/openaccess/ scholarly_guide.shtml).

The potential benefits of such a change are vast. No longer will physicians have to base their practice on half truths. Instead, everyone from patients to policymakers can read for themselves the evidence on which crucial science and health policy decisions are made. One example of a paper with potentially profound public health implications is the first randomized trial of male circumcision to prevent HIV infection (DOI: 10.1371/journal.pmed.0020298)having this paper and all related discussions freely available has allowed a lively, informed debate to flourish.

Will poorly funded researchers be excluded from publishing in openaccess journals? This concern is addressed by publishers such as PLoS and BMC, who waive fees for authors who cannot pay, and who strictly separate decisions on publication from ability to pay. This is not a radical departure into subsidies, but an accepted part of distributing publishing costs across the scientific community.

Increasingly, funders of research also realize the benefit of an openaccess model of publishing. The United Kingdom's Wellcome Trust (http://www.wellcome.ac.uk/ doc_WTD002766.html) mandates its funded authors to make their work publicly available; the United States National Institutes of Health are encouraging it (http://publicaccess. nih.gov), and governments and funding bodies are signing up to declarations on open access (http://www.zim.mpg.de/openaccessberlin/berlindeclaration.html).

By regaining control of copyright, the medical and scientific communities could ensure that publishing is no longer driven by the interests of publishers, but rather by the needs of society.

Citation: The PLoS Medicine Editors (2006) The impact of open access upon public health. PLoS Med 3(5): e252.

DOI: $10.1371 /$ journal.pmed.0030252

Copyright: $\odot 2006$ The PLoS Medicine Editors. This is an open-access article distributed under the terms of the Creative Commons Attribution License, which permits unrestricted use, distribution, and reproduction in any medium, provided the original author and source are credited.

E-mail: medicine_editors@plos.org

This Editorial is co-published in The Bulletin of the World Health Organization as part of a theme issue on intellectual property and public health. DOI: 10.2471/ BLT.06.032409 